\title{
MACHINING OF DIFFICULT-TO-CUT MATERIALS
}

\author{
Friedrich Bleicher, Daniel Finkeldei \& Anton Siller
}
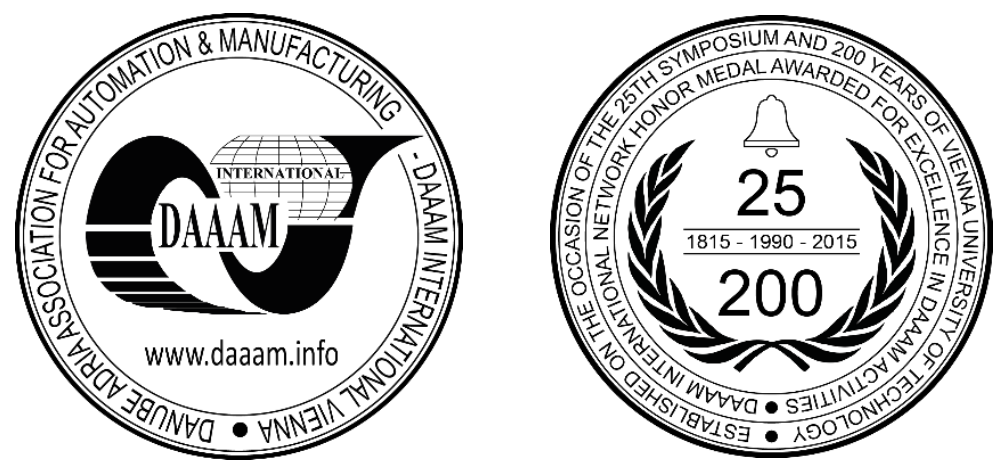

This Publication has to be referred as: Bleicher, F[riedrich]; Finkeldei, D[aniel] \& Siller, A[nton] (2016). Machining of Difficult-To-Cut Materials, Proceedings of the 27th DAAAM International Symposium, pp.0473-0479, B. Katalinic (Ed.), Published by DAAAM International, ISBN 978-3-902734-08-2, ISSN 1726-9679, Vienna, Austria DOI: $10.2507 / 27$ th.daaam.proceedings.071

\begin{abstract}
Austenitic steels are used in different areas of application where high strength and corrosion resistance are necessary at low and intermediate temperature levels. Machining these materials therefore induces high mechanical and thermal loading and reduces tool life and the overall process performance. A well-known approach to raise tool life is to dissipate the heat from the cutting edge. This paper presents some findings of a combined externally and internally cooled cutting insert compared to a solely externally cooled cutting insert.
\end{abstract}

Keywords: longitudinal turning; austenitic stainless steel, internally cooled insert, tool wear, tool lifetime

\section{Introduction}

Austenitic stainless steels are a group of corrosion resistant materials mainly used for components of industrial manufacturing [1]. With an increasing amount of nickel (up to 50\%) as its alloying element, austenitic steels become nickel alloys [2].

Fig. 1 summarizes the material properties of two most widespread austenitic steels and the nickel based alloy Inconel 718. Latter is more heat-resistant and shows higher hardness and strength. However, its elongation and thermal conductivity are significantly lower.

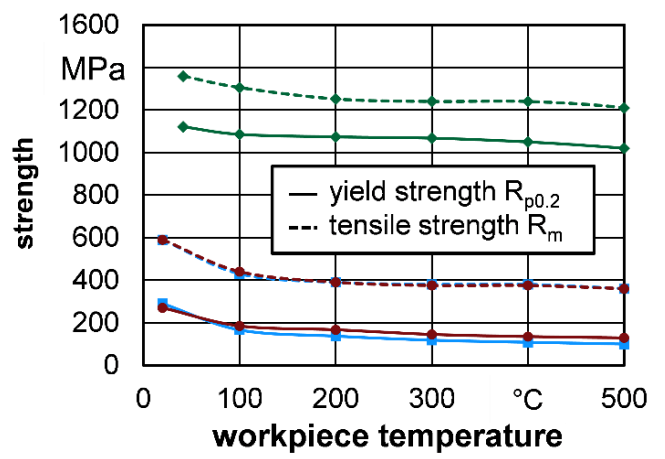

\begin{tabular}{lll|}
\hline$\rightarrow$ AISI 316 & & \\
$\rightarrow$ AISI $316 \mathrm{Ti}$ & & \\
$\rightarrow$ Inconel 718 & & \\
& & \\
density: & $8 \mathrm{~kg} / \mathrm{dm}^{3}$ & $\left(8.19 \mathrm{~kg} / \mathrm{dm}^{3}\right)$ \\
mod. of elast:: & $200 \mathrm{GPa}$ & $(211 \mathrm{GPa})$ \\
poissons ratio: & 0.3 & $(0.29)$ \\
elongation $\mathrm{A}_{5}:$ & $55 \%$ & $(23.5 \%)$ \\
hardness: & $160 \ldots 165 \mathrm{HB}$ & $(376 \mathrm{HB})$ \\
therm. conduct:: & $15 \mathrm{~W} / \mathrm{m} \cdot \mathrm{K}$ & $(11.4 \mathrm{~W} / \mathrm{m} \cdot \mathrm{K})$ \\
heat capacity: & $500 \mathrm{~J} / \mathrm{kg} \cdot \mathrm{K}$ & $(435 \mathrm{~J} / \mathrm{kg} \cdot \mathrm{K})$ \\
\hline
\end{tabular}

Fig. 1. Material properties of typical Cr-Ni-Mo stainless steels and Inconel 718 (values written in braces) [3, 4] 
The applications of austenitic stainless steels in the field of the process industry are in "pulp and paper, textile, food and beverages, pharmaceutical (and) medical (...) processing equipment" [3]. In nuclear power stations these alloys are used for instruments in the reactor, in marine applications e.g. as components of submarines or off-shore wind power plants [1]. Another major field of application is coming from the automotive industry in exhaust gas systems [1]. Nevertheless, main application of these materials is for pipes and fittings for the water supply of apartments and houses $[5,6]$. Some petrochemical applications use the austenitic steel AISI 317L or the relatively new P750 for clads, vessels, tubes, valves and other components in oil refineries [7].

The six important alloying elements in austenitic stainless steels are chromium, molybdenum, nickel, manganese, carbon and nitrogen. Nickel and nitrogen are austenite stabilizers who increase the resistance against stress-corrosioncracking [8] while nitrogen "forms an interstitial solid solution which disrupts dislocation motion and strengthens the steel" [9]. Manganese is a substitution element for nickel and builds up a protective layer of manganese sulphite in sulphurous atmosphere [8]. Chromium supports the corrosion resistance while molybdenum reduces the tendency for pitting and crevice corrosion [8].

Their high strength at room temperature as well as elevated temperatures combined with their low thermal conductivity makes stainless steels difficult to machine. With increasing cutting speed, the temperature at the cutting tool will raise proportionally [10]. The cutting temperature (at the cutting tool tip) is proportional to the cutting speed and below a critical feed rate chatter could result [10]. In addition, because of the ductile material behaviour and the formation of a big, instable Built-Up-Edge (BUE), high surface roughness is observed at higher cutting speeds [11]. For the end-milling process, the use of a system with ultrasonic-assistance resulted in a slightly worse roughness than in conventional milling [12]. Another technology was investigated by Shi and Attia [13]. They analysed cutting forces, workpiece temperature and flow stress during laser-assisted machining of an austenitic steel with a FEM simulation model [13]. Anderson and Shin [9] conducted laser-assisted machining experiments with the austenitic stainless steel P550. With increasing workpiece temperature, tool wear, specific cutting energy and surface roughness decreased. However, depositions of $\mathrm{Cr}_{2} \mathrm{~N}$ and $\sigma$-phase in the microstructure of the material were observed [9]. The following investigations focused on the machining behaviour under dry cutting conditions and under variation of the coating material of the cemented carbides. Kulkarni et al. [14] e.g. conducted high-speed-machining experiments with coated cemented carbide tools using the HPPMS coating process with AlTiCrN [14]. In comparison with Korkut et al. and Ciftci [15, 16], who used coated cemented carbide tools with multi-layers of TiCN-TiC- $\mathrm{Al}_{2} \mathrm{O}_{3}$ and TiC-TiCN-TiN, the AlTiCrN-coated tools led to a decrease of surface roughness by a factor of 2 to 3 and, because of the smoother tool surface, cutting and feed forces were reduced as well [14]. Selvaraj et al. [17] performed a turning experiment in dry cutting of austenitic stainless steel AISI 304. Using the Taguchi design of experiments method, they optimized the cutting parameters to obtain a minimum surface roughness [17].

Cooling lubricants have a significant influence on the machining process to raise tool life and improve surface finish. In contrast to conventional coolants, Jayadas et al. [18] and Xavior et al. [11] conducted research on coconut oil as a substitution medium [18] with positive results with respect to tool wear and surface roughness [11]. In the past, the use of minimum quantity lubrication (MQL) resulted in improved cutting behaviour for steels and other materials. Different studies discuss the advantages of MQL in machining [19-22]. Dureja et al. [23] did a parameter study based on the Taguchi orthogonal array robust design method. Using this lubricating technique, very low surface roughness was achieved [23]. Another study of Maruda et al. [24] was concerned with the ratio of chip compression and the influence of the shear angle and friction coefficient. They varied cutting speed and feed rate and studied the effects of MQL and dry cutting process [24]. Zhang et al. [25] applied an approach of the specific energy consumption to describe the surface roughness for increased cutting parameters [25]. Other researcher used cryogenic cooling for machining of stainless steels. Mayer et al. [26] studied different cooling methods supplying the process and the tool with liquid nitrogen $\left(\mathrm{LN}_{2}\right)$ and carbon dioxide snow $\left(\mathrm{CO}_{2}\right)$. Besides external cooling, they used internal coolant supply for local cooling of the tool tip. The tool froze due to the intense heat removal, leading to thermal shrinkage of the tool [26]. A further investigation focused on the turning process while cooling with cryogenic carbon dioxide snow $\left(\mathrm{CO}_{2}\right)$. For differently prepared cutting inserts, changes in the microstructure of $\alpha$ '-martensite as well as the surface roughness were observed [27]. Bleicher et al. [28, 29] designed an innovative cooling approach in which cutting inserts are cooled externally or internally with conventional coolant supplied by the machinery. Compared to cryogenic cooling, the cooling temperature is marginally higher and the heat dissipates directly from the tool tip without any thermal shrinking of the tool as observed by Mayer et al. [26]. This cooling strategy shows excellent results for the machining of aluminium and cast iron hybrid components [28, 29]. For this reason, using the same cooling approach is expected to show promising results also for machining of austenitic stainless steels.

\section{Experimental setup}

The used workpiece material is P750, an austenitic chromium-nickel-nitride stainless steel developed for oil field industry applications. The material properties are comparable to those of conventional austenitic steels (see

Fig. 1). Its yield and tensile strength are $900 \mathrm{MPa}$ and $1035 \mathrm{MPa}$, respectively. Its hardness is $32 \ldots 43 \mathrm{HRC}$ and its elongation of $15 \%$ is approximately $40 \%$ lower than that of conventional austenitic stainless steels. The tool material is a TiAlN-coated cemented carbide with a triangular shape form as of ISO definition TCGT 16 T3 08-UM. The clearance angle $\alpha$ is $7^{\circ}$, the rake angle $\gamma 9^{\circ}$, the corner angle $\varepsilon 60^{\circ}$ and the cutting edge radius $\mathrm{r}_{\varepsilon} 6 \mu \mathrm{m}$. The experimental setup is shown in Fig.2. 


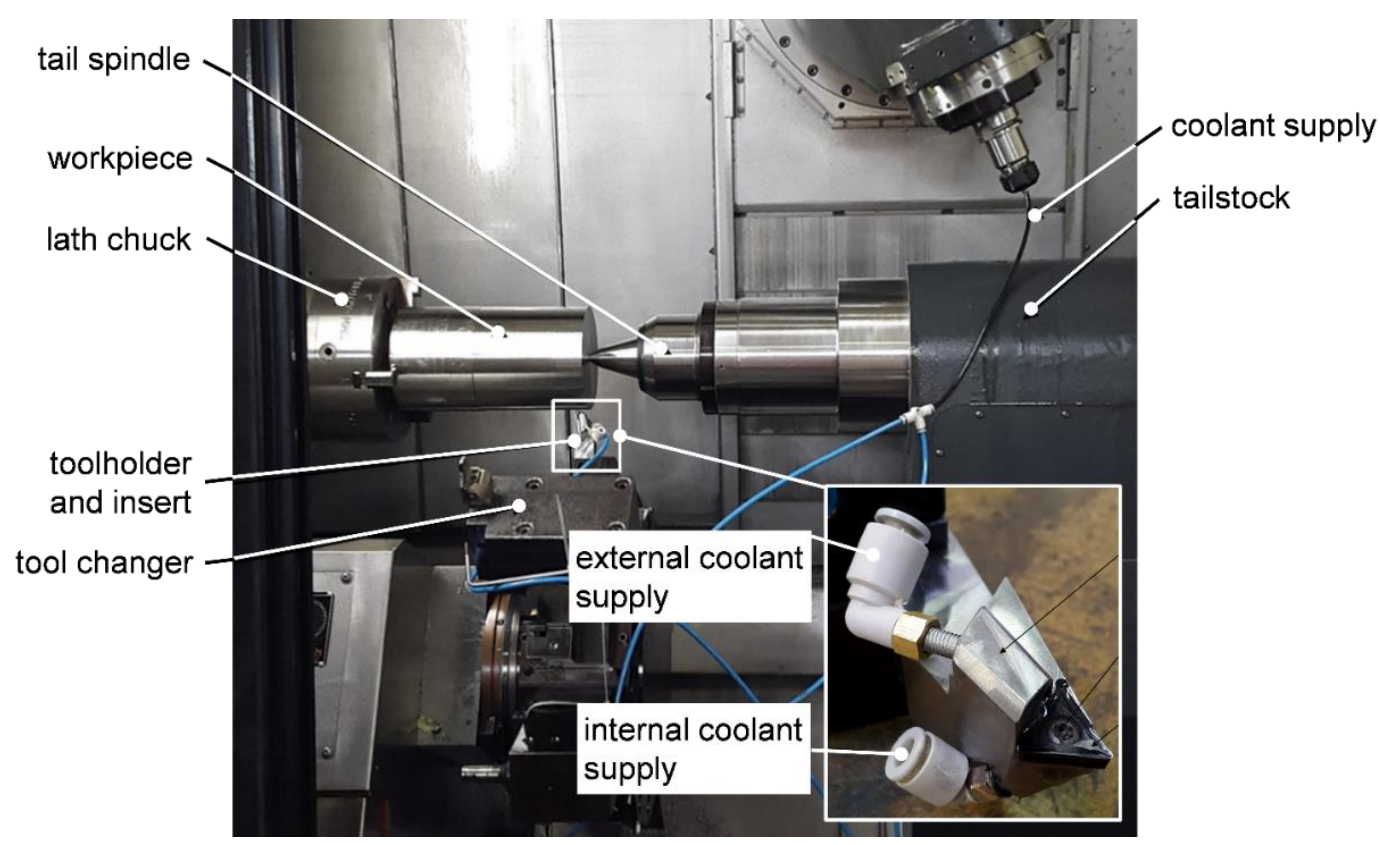

Fig. 2. Experimental setup of the turning process

In order to examine the effect of the coolant supply strategy, three options were considered. At first, the coolant was supplied externally over the rake face, secondly only internally through the tool insert whereas in the third option both external and internal cooling was used. For every internal supply strategy the flow volume of the coolant through the toolholder was set to $0.6 \% \mathrm{~min}$. The design of experiment is shown in Table 1 . To validate the behaviour of the tools under these experimental variations, the tool wear was measured with a Keyence VW600C microscope with a magnification factor of up to 200. Three dimensional images of the tool tip were additionally obtained on an Alicona InfiniteFocus G4 measurement system.

\begin{tabular}{ll}
\hline Experimental design & Setup 1 \\
\hline cutting speed $\mathrm{v}_{\mathrm{c}}$ & $100 \mathrm{~m} / \mathrm{min}$ \\
feed rate $\mathrm{f}$ & $0.1 \mathrm{~mm} / \mathrm{rev}$ \\
depth of cut $\mathrm{a}_{\mathrm{p}}$ & $0.5 \mathrm{~mm}$ \\
tool coating & TiAlN-coated \\
cooling/lubrication strategies & external cooling \\
& internal cooling \\
& external + internal cooling \\
flow volume through the toolholder & $0.61 / \mathrm{min}$ \\
\hline
\end{tabular}

Table 1. Design of Experiment

The machining process was stopped as soon as one of the following tool wear criteria was exceeded:

1. Tool wear land $\mathrm{VB}_{\max }$ exceeds $250 \mu \mathrm{m}$

2. Tool notch wear $\mathrm{VB}_{\text {notch }}$ exceeds $200 \mu \mathrm{m}$

3. Crumbling of the cutting edge larger than $150 \mu \mathrm{m}$

4. Process time larger than $90 \mathrm{~min}$

\section{Experimental results}

For all of the three cooling strategies the development of flank wear reached the linear wear progression zone after a cutting time of $6 \mathrm{~min}$ (see Fig. 3). While tool wear on the flank and rake face was uncritical, there was a tribo-chemical reaction on the flank face. For the externally and combined cooled insert, the tribo-chemical reaction was more profound but localized on a certain part of the flank face (shown in the middle and right upper image of Fig. 4). On the other hand, the tribo-chemical reaction under the internal cooling condition was more transparent and distributed over the whole tool contact area. 


\begin{tabular}{llll|}
\hline tool: & TCGT 16 T3 08-UM & cutting speed: & $\mathrm{v}_{\mathrm{c}}=100 \mathrm{~m} / \mathrm{min}$ \\
coating: & TiAIN & feed rate: & $\mathrm{f}=0.1 \mathrm{~mm}$ \\
material: & P750 austenitic steel & depth of cut: & $\mathrm{a}_{\mathrm{p}}=0.5 \mathrm{~mm}$ \\
\hline
\end{tabular}

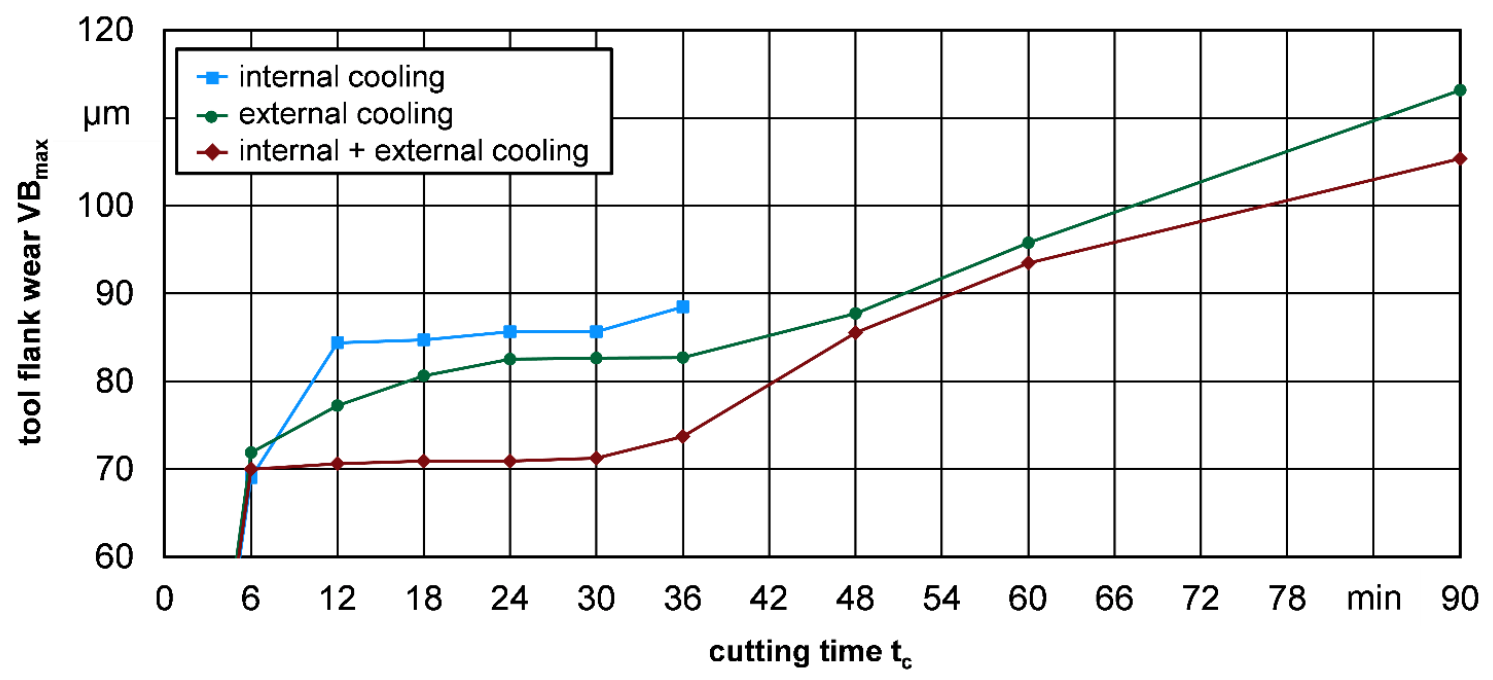

Fig. 3. Visualisation of tool wear over cutting time

After a cutting time of 36 min, significant changes in tool wear occurred (see Fig. 5). The tribo-chemical reaction (described in

Fig. 6) under the external and combined cooling method increases slightly. The flank face with the internally cooled insert had a strong scaling, as observable by the discoloured shape of tribo-chemical surface (seen on the left upper image of Fig. 5). Furthermore, notch wear can be observed on the cutting edge along the flank and rake face. The lack of lubrication fluid is a logical explanation for this wear behaviour. For the machining process, high-strength austenitic stainless steels require some lubrication to reduce friction and, as a consequence of this, the abrasive tool-wear.

\begin{tabular}{llll|}
\hline tool material: & cemented carbide & cutting speed: & $\mathrm{v}_{\mathrm{c}}=100 \mathrm{~m} / \mathrm{min}$ \\
tool insert: & TCGT 16 T3 08-UM & feed rate: & $\mathrm{f}=0.1 \mathrm{~mm}$ \\
coating: & TiAIN & depth of cut: & $a_{\mathrm{p}}=0.5 \mathrm{~mm}$ \\
material: & P750 austenitic steel & cutting time: & $\mathrm{t}_{\mathrm{c}}=6 \mathrm{~min}$ \\
\hline
\end{tabular}
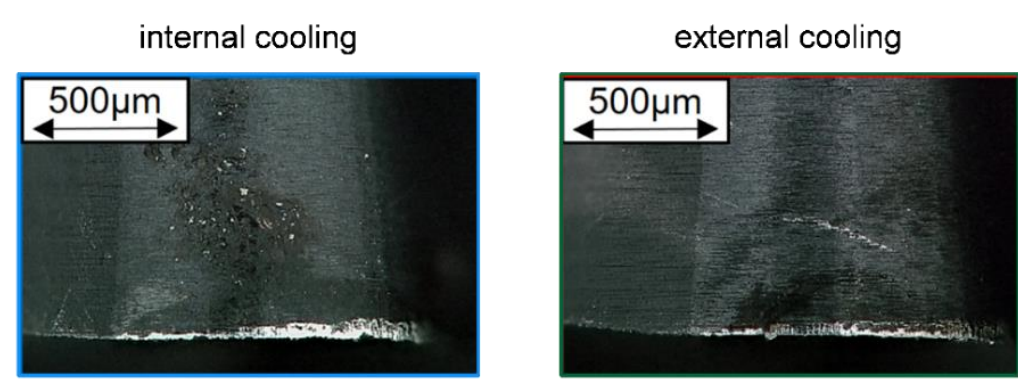

internal + external cooling
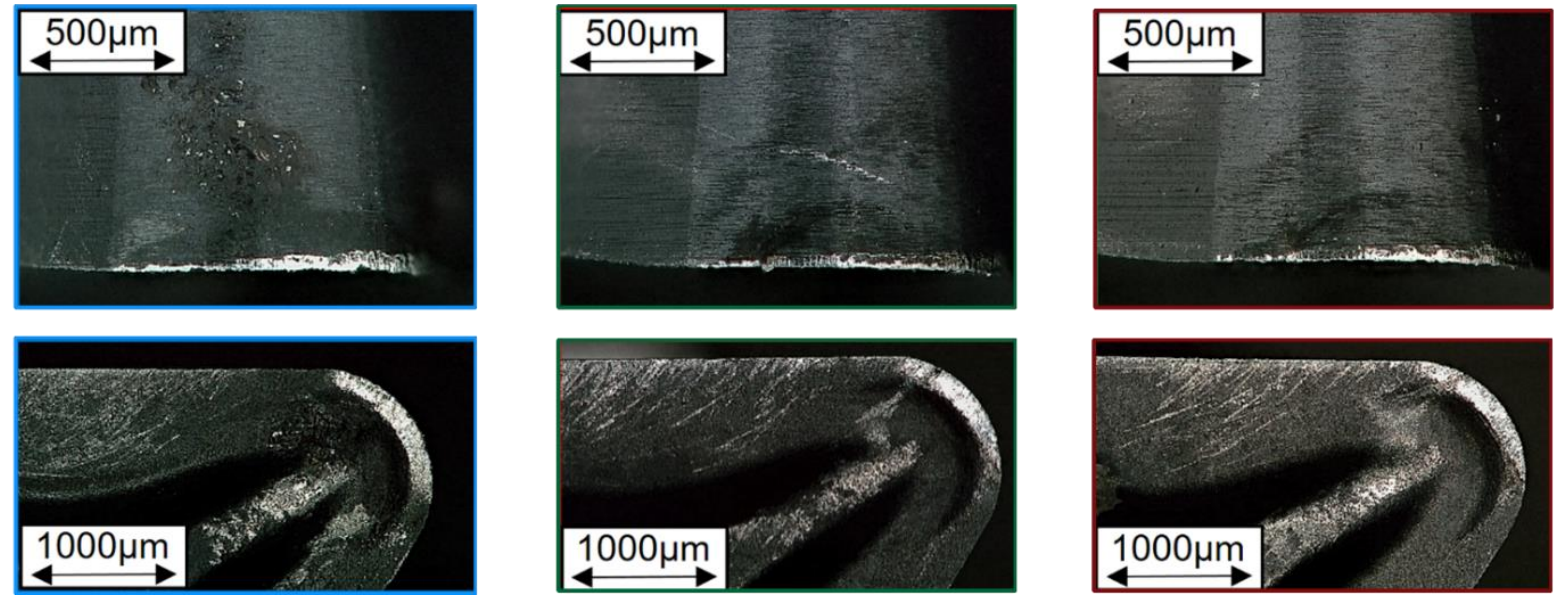

Fig. 4. Tool wear of the rake and flank face after a cutting time of $6 \mathrm{~min}$

In comparison to the two other cooling strategies, the rapidly increasing tribo-chemical wear leads to a stop of the machining process with the internally cooled insert without reaching the tool wear criteria. Additionally, the machining process under the external and combined cooling performed up to a cutting time of 90 min (seen in

Fig. 6). In this situation, notch and flank wear increased with both strategies (seen in the red circles of

Fig. 6). The tribo-chemical reaction is more distinct on the tool flank face for the external cooling strategy. 


\begin{tabular}{|llll|}
\hline \hline & & & \\
\hline tool material: & cemented carbide & cutting speed: & $\mathrm{v}_{\mathrm{c}}=100 \mathrm{~m} / \mathrm{min}$ \\
tool insert: & TCGT 16 T3 08-UM & feed rate: & $\mathrm{f}=0.1 \mathrm{~mm}$ \\
coating: & TiAIN & depth of cut: & $a_{p}=0.5 \mathrm{~mm}$ \\
material: & P750 austenitic steel & cutting time: & $t_{c}=36 \mathrm{~min}$ \\
\hline
\end{tabular}
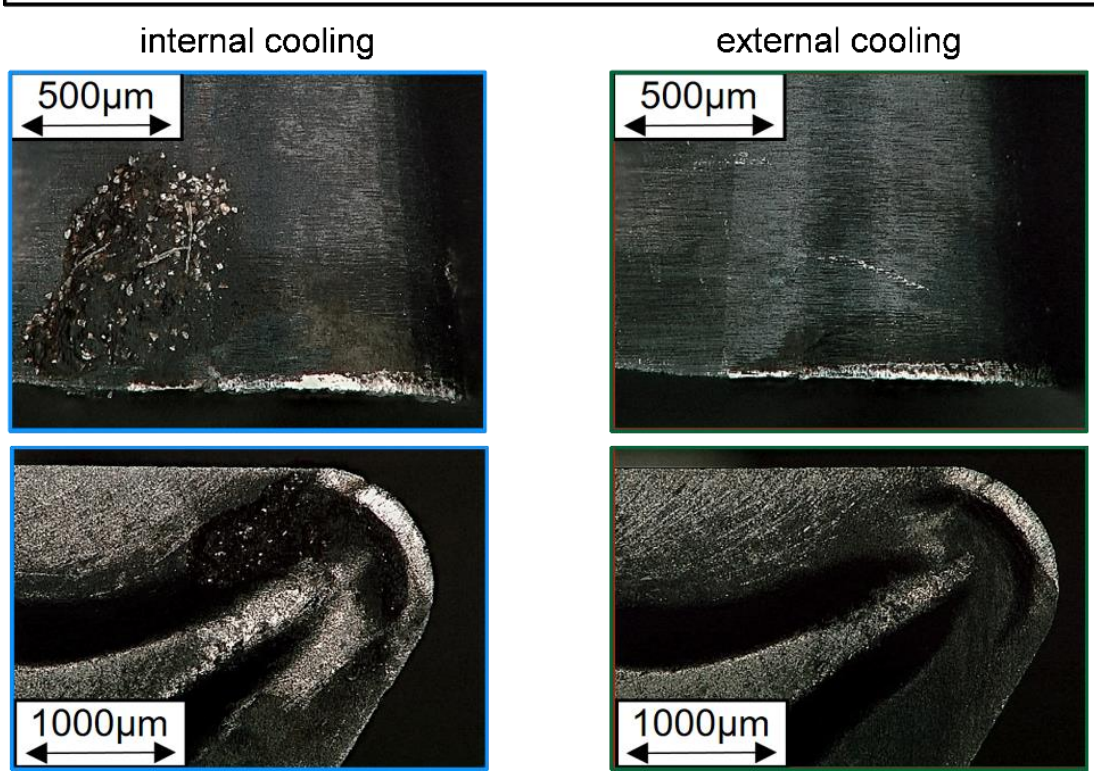

internal + external cooling

Fig. 5. Tool wear of the rake and flank face after a cutting time of $36 \mathrm{~min}$

Fig. 7 shows three dimensional images of cutting edges using both cooling strategies. The tool notch wear is visible on the right side of the picture. Using the external cooling technique, a shattered surface of the cutting tool along the rake and flank face occurs during machining. The combined cooling strategy stabilized the resistance of the cutting tool edge against tool wear.

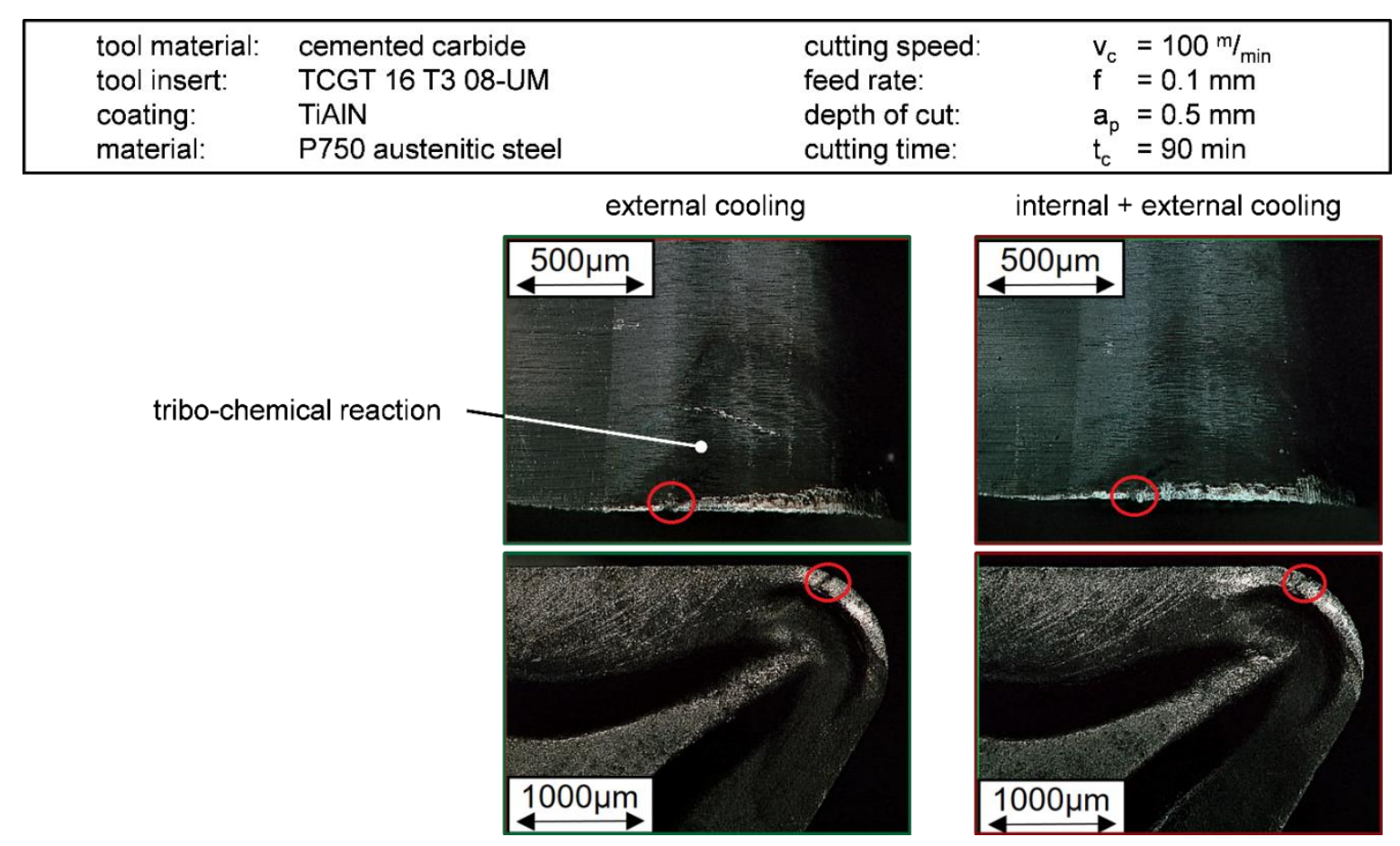

Fig. 6. Tool wear of the rake and flank face after a cutting time of $90 \mathrm{~min}$

Over the whole machining time of $90 \mathrm{~min}$, the combined cooling technique reduced tool wear as it is observable by smaller wear land along the cutting edge. However, between cutting times of $36 \mathrm{~min}$ and 60 min the wear progression curves of the external and combined cooling strategies converged (see Fig. 3). Because of the large step range of 6 min, the degressive character of the starting phase of the tool wear progression could not be shown. However, the focus of this work was to investigate the tool wear behaviour at intermediate cutting times. 


\begin{tabular}{llll|}
\hline & & & \\
\hline tool material: & cemented carbide & cutting speed: & $\mathrm{v}_{\mathrm{c}}=100 \mathrm{~m} / \mathrm{min}$ \\
tool insert: & TCGT 16 T3 08-UM & feed rate: & $\mathrm{f}=0.1 \mathrm{~mm}$ \\
coating: & TiAIN & depth of cut: & $a_{\mathrm{p}}=0.5 \mathrm{~mm}$ \\
material: & P750 austenitic steel & cutting time: & $t_{c}=90 \mathrm{~min}$ \\
\hline
\end{tabular}
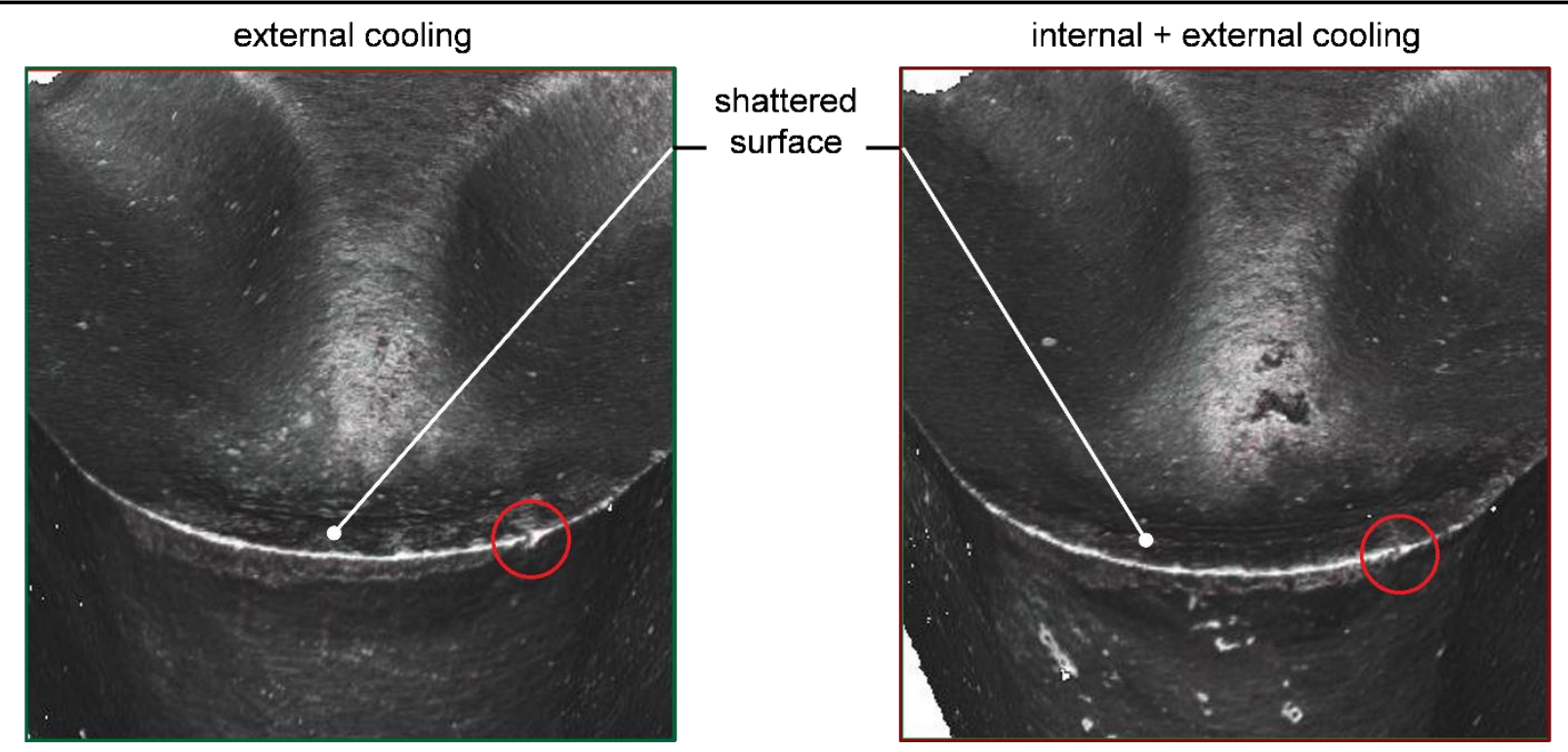

Fig. 7. Three dimensional image of worn tools

\section{Conclusion}

The purpose of this study was to investigate the tool wear behaviour in machining the high-strength austenitic stainless steel P750 with an internal cooling strategy. When machining this material i.a. high thermal and mechanical tool load emerged near the cutting edge and increase the temperature inside the tool and hence tool wear. Based on a study of Bleicher et al. [28, 29], conventional coolant was led through the cutting insert to dissipate heat directly near the cutting edge. The internal cooling strategy combined with an external coolant supply resulted in a reduction of tool wear when machining P750. In order to reduce tool wear, lubrication is a necessity and an important factor of the cutting process. Low cutting speeds are chosen in this study. To validate the discussed results and to observe the machining behaviour under the applied cooling strategies, higher cutting speeds could be used in a further investigation. Moreover, subsequent studies could focus on an investigation of machining with the internal cooling technique based on minimum quantity lubrication. Besides tool life, the surface finish could be examined as well in order to draw conclusions on the workpiece quality.

\section{References}

[1] Montanstahl (2016): Datasheet about special steel profiles, http://www.montanstahl.at/de/1.4401, Stand: 07.08.2016 [2] Heubner, U. (1998): Nickel alloys and high-alloy special stainless steels - materials summary and metallurgical principles. In: Nickel Alloys, edited by Heubner, U., pp. 1-43

[3] Outokumpu (2006): Datasheet of Standard Cr-Ni-Mo stainless steels, https://www.outokumpu.com/SiteCollectionDocuments/Standard_Cr-Ni-Mo_Stainless_Steels_Datasheet.pdf

[4] Bibus Metals AG (2016): Datasheet of INCONEL Alloy 718, https://www.bibusmetals.ch

[5] Montanstahl (2016): Datasheet about special steel profiles, http://www.montanstahl.at/de/1.4571, Stand: 07.08.2016 [6] Avery, RE; Lamb, S.; Powel, C.A.; Tuthill, A.H. (2016): Stainless steel for potable water treatment plants (PWTP). In: Nickel Development Institute,

https://www.nickelinstitute.org/ /media/Files/TechnicalLiterature/10087_StainlessSteelForPotableWaterTreatmentPlan ts.ashx

[7] Farneze, H.N.; Ravares, S.S.M.; Pardal, J.M. (2015): Effects of Thermal Aging on Microstructure and Corrosion Resistance of AISI 317L Steel Weld Metal in the FSW Process. In: Materials Research, 18(Suppl. 2), pp. 98-103

[8] Jones, R.H. (2005): Environmental Effects in Engineered Materials. New York: Marcel Dekker, Inc.

[9] Anderson, M.C.; Shin, Y.C. (2006): Laser-assisted machining of an austenitic stainless steel: P550. In: Journal of the Engineering Manufacture, 220, pp. 2055-2067

[10] Lin, W.S. (2008): The study of high speed fine turning of austenitic stainless steel. In: Journal of Achievements in Materials and Manufacturing Engineering, 27, pp. 191-194 
[11] Xavior, M.A.; Adithan, M. (2009): Determining the influence of cutting fluids on tool wear and surface roughness during turning of AISI 204 austenitic steel. In: Journal of Materials Processing Technology, 209, pp. 900-909

[12] Maurotto, A.; Wickramarachi, C.T. (2016): Experimental investigations on effects of frequency in ultrasonicallyassisted end-milling of AISI 316L: A feasibility study. In: Ultrasonics, 65, pp. 113-120

[13] Shi, B.; Attia, H. (2013): Integrated Process of Laser-Assusted Machining and Laser Surface Heat Treatment. In: Journal of Manufacturing Science and Engineering, 135

[14] Kulkarni, A.P.; Joshi, G.G.; Sargade, V.G. (2013): Dry turning of AISI 304 austenitic stainless steel using AlTiCrN coated insert produced by HPPMS technique. In: Procedia Engineering, 64, pp. 737-746

[15] Korkut, I.; Kasap, M.; Ciftci, I.; Seker, U. (2004): Determination of optimum cutting parameters during machining of AISI 304 austenitic stainless steel. In: Material and Design, 25, pp. 303-305

[16] Ciftci, I. (2006): Machining of austenitic stainless steels using CVD multi-layer coated cemented carbide tools. In: Tribology Internation, 39, pp. 565-569

[17] Selvaraj, D.; Chandramohan, P. (2010): Optimization of surface roughness of AISI 304 austenitic stainless steel in dry turning operation using taguchi design method. In: Journal of Engineering Science and Technology, 5 no. 3, pp. 293301

[18] Jayadas, N.H.; Prabhakaran Nair, K. (2006): Coconut oil as base oil for industrial lubricants - evaluation and modification of thermal, oxidative and low temperature properties. In: Tribology International, 39, pp. 873-878

[19] Weinert, K.; Insaki, I.; Sutherland, J.W.; Wakabayashi, T. (2004): Dry machining and minimum quantity lubrication. In: Annals of the CIRP, 53, pp. 511-537

[20] Attanasio, A.; Gelfi, M.; Giardini, C.; Remino, C. (2006): Minimal quantity lubrication in turning: Effect on tool wear. In: Wear, 260, pp. 333-338

[21] Liao, Y.S.; Lin, H.M. (2007): Mechanism of minimum quantity lubrication in high-speed milling of hardened steel. In: International Journal of Machine Tools \& Manufacture, 47, pp. 1660-1666

[22] Zhang, S.; Li, J.F.; Wang, Y.W. (2012): Tool life and cutting forces in end milling Inconel 718 under dry and minimum quantity cooling lubrication cutting conditions. In: Journal of Cleaner Production, 32, pp. 81-87

[23] Dureja, J.S.; Singh, R.; Singh, T.; Singh, P.; Dogra, M.; Bhatti, M.S. (2015): Performance Evaluation of Coated Carbide Tool in Machining of Stainless Steel (AISI 202) under Minimum Quantity Lubrication (MQL). In: International Journal of Precision Engineering and Manufacturing-Green Technology, 2, pp. 123-129

[24] Maruda, R.W.; Krolczy, G.M.; Nieslony, P.; Krolczyk, J.B.; Legutko, S. (2016): Chip formation zone analysis during the turning of austenitic stainless steel 316L under MQCL cooling condition. In: Procedia Engineering, 149, pp. 297-304 [25] Zhang, Y.; Zou, P.; Li, B.; Liang, S. (2015): Study on optimized principles of process parameters for environmentally friendly machining austenitic stainless steel with high efficiency and little energy consumption. In: International Journal of Advanced Manufacturing Technology, 79, pp. 89-99

[26] Mayer, P.; Skorupskim, R.; Smaga, M.; Eifler, D.; Aurich, J. (2014): Deformation induced surface hardening when turning metastable austenitic steel AISI 347 with different cryogenic cooling strategies. In: Procedia CIRP, 14, pp. 101106

[27] Mayer, P.; Kirsch, B.; Müller, R.; Becker, S.; von Harbou, E.; Aurich, J. (2016): Influence of cutting edge geometry on deformation induced hardening when cryogenic turning of metastable austenitic stainless steel AISI 347. In: Procedia CIRP, 45, pp. 59-62

[28] Bleicher, F.; Brier, J.; Siller, A. (2016): Simultaneous machining of a material combination with an internally and externally cooled cutting insert. In: Procedia CIRP, 46, pp. 15-18

[29] Bleicher, F.; Pollak, C.; Brier, J.; Siller, A. (2016): Reduction of built-up edge formation in machining Al- and cast iron hybrid components by internal cooling of cutting inserts. In: Annals of the CIRP - Manufacturing Technology, 65, pp. 97-100 